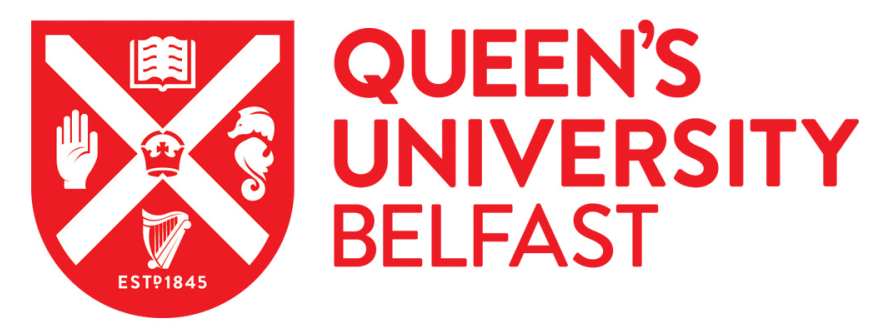

\title{
Perceptions of exercise among people who have not attended cardiac rehabilitation following myocardial infarction
}

\author{
McCorry, N. K., Corrigan, M., Tully, M. A., Dempster, M., Downey, B., \& Cupples, M. E. (2009). Perceptions of \\ exercise among people who have not attended cardiac rehabilitation following myocardial infarction. Journal of \\ Health Psychology, 14(7), 924-932. https://doi.org/10.1177/1359105309341144
}

Published in:

Journal of Health Psychology

Document Version:

Peer reviewed version

Queen's University Belfast - Research Portal:

Link to publication record in Queen's University Belfast Research Portal

Publisher rights

(C) 2009 SAGE.

This work is made available online in accordance with the publisher's policies. Please refer to any applicable terms of use of the publisher.

\section{General rights}

Copyright for the publications made accessible via the Queen's University Belfast Research Portal is retained by the author(s) and / or other copyright owners and it is a condition of accessing these publications that users recognise and abide by the legal requirements associated with these rights.

Take down policy

The Research Portal is Queen's institutional repository that provides access to Queen's research output. Every effort has been made to ensure that content in the Research Portal does not infringe any person's rights, or applicable UK laws. If you discover content in the Research Portal that you believe breaches copyright or violates any law, please contact openaccess@qub.ac.uk. 


\section{RUNNING HEAD: PERCEPTIONS OF EXERCISE OF CR NON-ATTENDERS}

Perceptions of Exercise among People who have not Attended Cardiac Rehabilitation

following Myocardial Infarction

Noleen K. McCorry

School of Psychology, Queen's University Belfast.

Mairead Corrigan

Division of Medical Education, Queen's University Belfast.

Mark A. Tully

Health and Rehabilitation Sciences Research Institute, University of Ulster.

Martin Dempster

School of Psychology, Queen's University Belfast.

Bernadette Downey

Cardiac Rehabilitation Department, Mater Hospital, Belfast Health \& Social Care Trust.

Margaret E. Cupples

Division of Public Health Medicine and Primary Care, Queen's University Belfast.

Corresponding author:

Noleen K. McCorry

School of Psychology

Queen's University Belfast

Belfast BT7 1NN

n.mccorry@qub.ac.uk

Tel: +44 2890975650

Fax: +44 2890975486 


\section{Acknowledgements}

We thank sincerely the general practice staff who participated in this study and the people who so willingly gave us their time and took part in interviews. We also wish to thank the other members of our study team- Professor Ian Young, Dr Gavin Dalzell, and Dr Damian

McCall. This research was supported by funding from the Research and Development Office for Health and Personal Social Services in Northern Ireland (Investing for Health

Programme). 


\begin{abstract}
Perceptions of exercise among non-attenders of cardiac rehabilitation (CR) were explored using semi-structured interviews. Analysis indicated that participants did not recognise the cardiovascular benefits of exercise, and perceived keeping active through daily activities as sufficient for health. Health professionals were perceived to downplay the importance of exercise and CR, and medication was viewed as being more important than exercise for promoting health. The content of CR programmes and the benefits of exercise need to be further explained to patients post-MI, and in a manner that communicates to patients that these programmes are valued by significant others, particularly health professionals.
\end{abstract}

Key words: cardiac rehabilitation; exercise; myocardial infarction; communication, perceptions 


\section{Introduction}

While cardiac rehabilitation (CR) has been shown to improve survival and help prevent another myocardial infarction (MI) (Taylor, Brown, Ebrahim, Jolliffe, Noorani, et al., 2004), attendance rates are low and adherence among those who initiate CR is poor (Witt, Jacobsen, Weston, Killian, Meverden, et al., 2004). Explanations for low attendance include various socio-demographic, clinical, and psychological variables (Cooper, Lloyd, Weinman, \& Jackson, 1999; Cooper, Jackson, Weinman, \& Horne, 2002; Witt, Thomas, \& Roger, 2005), as well as non-patient related variables such as the perceived strength of physician recommendation (Ades, Waldman, McCann \& Weaver, 1996), the type of consultant (Pell, Pell, Blatchford \& Dargie, 1996), and not receiving an outpatient appointment (Melville, Packham, Brown, Weston \& Gray, 1999). Leventhal's selfregulatory model (Leventhal, Meyer \& Nerenz, 1980) proposes that illness beliefs may direct the way in which individuals cope with their illness, and therefore provides a rationale for behaviours such as medication adherence and attendance at cardiac rehabilitation programmes.

Key illness beliefs have been linked to non-attendance in several qualitative and quantitative studies (Ades et al., 1996; Cooper et al., 1999; MacInnes, 2005; Petrie, Weinman, Sharpe, \& Buckley, 1996; Whitmarch, Koutantji, \& Sidell, 2003; Wyer, Joseph, \& Earl, 2001). However, these factors do not fully explain the problem: findings in relation to illness perceptions have been inconsistent and effect sizes have been found to be small (French, Cooper, \& Weinman, 2006; French, Lewin, Watson, \& Thompson, 2005). It has been suggested that exploration of CR perceptions (rather than illness perceptions) may add considerably to the explanation of non-attendance (French et al. 2006; Cooper, Weinman, Hankins, Jackson \& Horne, 2007), and several studies (Clark, Whelan, Barbour, \& 
MacIntyre, 2005; Cooper et al., 2007; Cooper, Jackson, Weinman \& Horne, 2005; Wyer, Earll, Joseph \& Harrison, 2001) have now highlighted concerns about exercise in relation to $\mathrm{CR}$ among non-attenders, embarrassment about group exercise, and clear misconceptions about the content of CR programmes, particularly regarding the exercise components. It would appear that, in order to influence beliefs about $\mathrm{CR}$, there is a need to further explore how men and women who are post-MI perceive exercise in the context of cardiac rehabilitation. Further study of non-attenders' attitudes to physical activity has also been recommended by Blanchard, Reid, Morrin, Beaton, Pipe et al. (2006).

Our study aims to explore in detail patients' beliefs about exercise for promoting recovery from a MI within the context of cardiac rehabilitation among men and women who did not attend a formal CR programme. Understanding patients' beliefs about exercise and its role in promoting recovery is important because these beliefs may be amenable to change, thus promoting CR attendance.

\section{Method}

The study received local research ethics committee approval. A stratified sample of 38 general practices was selected to represent the distribution of geographical location and practice size in Northern Ireland. Primary care staff from these practices were asked to identify prospectively, from hospital discharge letters, all patients who had a MI between February 2005 and November 2006 and to invite them to participate in a study relating to cardiac rehabilitation invitation and attendance. Twelve to sixteen weeks after their MI consenting participants were asked to complete a postal questionnaire of sociodemographic information and history of CR attendance. Participants were also given information about the interview phase of the study and asked to consent to further contact from the research team in relation to this. 
From the responses received we identified participants who had not attended CR. From these non-attenders, an initial sample of male and female patients of varying age, socio-economic background and geographical location were purposively selected for interview - in a manner which maximized variability on these characteristics. Participants were invited by telephone to take part in semi-structured interviews in their home. 18 patients were invited for interview. Two declined to be interviewed, and a further two were found to have actually attended a CR programme and were therefore not eligible. Our final sample consisted of fourteen patients, eight men and six women, ranging from 34-82 years in age with a mean of 64 years. Most of the interviews were conducted approximately one year following MI (range 7-22 months). Two researchers conducted the interviews, all of which were tape-recorded and transcribed verbatim, with the participants' consent.

A flexible interview schedule was developed to ensure that the main issues were covered but which allowed the researchers to ask other questions and to incorporate emergent issues which in turn influenced the sampling of further participants (e.g. those with/without co-morbid medical conditions) to facilitate a deeper exploration of these issues. This iterative approach allowed the research questions to be refined as the interviews progressed, and provided a sensitivity to the richness and variability of the subject matter (Creswell, 2003; Greenhalgh \& Taylor, 1997).

The interviews began by asking participants to describe their experience of MI, and the information they received about CR, exercise and lifestyle changes. Interviews progressed to explore participants' perceptions of exercise in relation to CR. Analysis of the interview data progressed in tandem with data collection and recruitment. In analyzing the data, each transcript was read and re-read a number of times to gain a thorough familiarization with the participant's account. Units of meaning which described the 
participant's data were then extracted and funneled into relevant themes. Emerging themes that appeared to be associated with each other within each transcript were grouped together, and a list of common themes between participants was generated. With continuous reference to the transcripts, the themes were summarized and organized to establish their interrelationships and generate a number of super-ordinate themes. A consolidated list of themes was produced, and new themes were tested against earlier transcripts in a cyclical fashion. The aim of this analytical process was to produce shared themes which added to an account of the meaning of the participants' shared experiences grounded in their own words. Extracts were selected which represented the most insightful or articulate expressions of a given theme. Two of the authors met regularly to develop and negotiate the emerging analytical framework. Recruitment continued until data saturation was reached and no new themes were seen to emerge from two successive interviews.

\section{Findings}

Analysis of the interview data yielded four higher order themes: limited value of CR exercise for long-term health; daily activity as sufficient and appropriate exercise; unconvincing messages from health professionals; and a hierarchy of illnesses. Limited value of CR exercise for long-term health

Conspicuously absent from the interview data was any acknowledgement that the exercises in formal CR programmes might be effective for secondary prevention, or for improving prognosis.

'After I got over the initial period of fear, I got more confident so I didn't feel I needed any support and I didn't want to be runnin' to places where I hadn't time to go... The cardiac rehab I suppose is just to reassure you...It wouldn't do anything for 
you medically... if you are feelin' ok you can do without it... The only fear I have is I

know heart attacks are unpredictable.' (5B; male, 65 yrs)

Adherence to medication was perceived to give greater personal control over health (and secondary prevention) and CR attendance was not perceived to provide additional value.

'I've been able to control all this heart business with medication, with checkups every so often.' (38H; female, 63 yrs)

Even participants who were engaged in regular exercise subscribed to a 'medical model' of illness, attributing their improved health to medication, and not to their exercise programme.

'Ifeel the tablets I'm taking have more of an impact on my health, that I'm feeling so much better ... and then that means I can do the walking so much better as well I suppose...I would put it down to the medication.' (23E, female, 72 yrs)

Moreover, CR exercises were not perceived as a mechanism for long term sustained behaviour change. They were viewed as a 'course' that enabled patients to return to a certain 'level' of functioning.

'There's certain exercises ... to sort of bring yourself back to normal again... But I seemed to bring myself back [to normal] so that I'm comfortable enough to wait for my operation, I don't suffer that much.' (8G; male; 78 yrs)

Some younger participants thought that a CR programme wasn't appropriate for them because they perceived attendees to be elderly, and the exercises within CR programmes as unsuited to a younger age-group.

'I'd another uncle had a heart attack... and he was saying about the age groups there and he put me off it even more...he was going on about what they were 
making him do, how to sit down in a chair, how to stand up, things like that there just didn't appeal to me.' (5H; male, 34 yrs)

Given the perceptions expressed about the value of exercise, it is unsurprising that only two (younger) participants identified lifestyle factors as contributing to their MI. Others attributed it to factors outside of their control (such as fate or familial disposition), or perceived it to be caused by stressful or emotional circumstances.

'If you have to shuffle off [die], it doesn't matter what you shuffle off with. My sister was 23 when she shuffled off with her heart, my daddy was 67, he died with his heart, mummy was 67 when she died with cancer, you know. By the same token, one of my mum's sisters was 96 when she died, the other one was 89. My daddy's sisters - some of them were 90 odd...If it's your time, it's your time. When you've got to go, you've got to go.' (1C; female, 83 yrs)

Daily activity as sufficient and appropriate exercise

Most participants appeared aware of advice that they should be physically active. However, the cardiovascular benefits of exercise were not mentioned by participants, who were more motivated to be active in order to maintain flexibility.

'... you are supposed to do a certain amount, as well I don't want to get stiffed up with pains you know. And I try to keep walking, to do things like that...' (38C; female, 75 yrs)

Most of the participants preferred to keep physically active through daily chores, shopping, or hobbies (such as recreational walking, dancing and gardening). None reported perceiving a need for additional exercise through $\mathrm{CR}$ attendance. They emphasised the social and psychological benefits of keeping physically active (spending time with family; reducing isolation; feeling more independent) over the physical benefits. 
There appeared to be a common belief that keeping active through social activities was a sufficient level of exercise.

'...I would wash the dishes there for the wife, and do things like that there, do wee bits in that garden ... keep myself exercising by doing that there. I have no need to go to [formal CR].' (7A; male, 71 yrs)

'...we walk down the street, and go round the shops ...so you're walking anyway. I really go just to be out...cause you get a bit depressed sitting in the house all the time.' (38C; female, 75 yrs)

Several participants described how they would walk at a leisurely pace and emphasised the importance of resting during the course of the activity, reflecting their concerns about straining the heart or becoming breathless through vigorous activities.

'My difficulty is at the minute, if I did do the half hour, I would suffer considerable discomfort, and then I don't know whether I'm doing myself any harm, or whether I'm doing myself any good. Chances are I'm probably doing myself good, providing I don't go overboard.' (30A; male, 60 yrs)

Activity which caused participants to breath more heavily was not thought to be appropriate. Co-morbid health problems also prevented or limited their ability to exercise. 'I wouldn't really get out of breath...If you were walking fast, and you feel that, you would just automatically slow up.' (8G; male, 78 yrs)

'I was always a walker... but now, I'm afraid really to over do things, cause I don't want to put a strain on my heart obviously.' (1C; female; 83 yrs)

'Well, you see, with the pain, with the arthritis you can't do an awful lot, you know. Sort of, you get tired, and then you get weak you know.' (38C; female, 75 yrs) 
Unconvincing messages from health professionals

Several participants recalled how health professionals had presented their invitation to $\mathrm{CR}$. They considered that the manner of invitation did not indicate that it was important to attend $\mathrm{CR}$.

'I think it was just a matter of form for them [health professionals], they just explain it to you, you had the option to go, and if you don't want to go you don't have to...If they had have pushed it that much, I would probably have gone to it at least once, just to see what they were on about.' (5H; male; 34yrs)

Advice related to exercise, which had been received from health professionals, appeared to have been non-specific, such as to 'keep active' or 'take it easy'. Participants reported that they had received information about other lifestyle changes, but not about exercise.

'It's never said to me that walking is a good thing. I just took it on myself to walk. But never at any stage did anybody say - now walk as much as you can. Except for the physiotherapist - she said walking was good. No doctors or anybody else said anything about walking.' (29D; male; 82yrs)

'I've been told what to avoid to eat and things like that - not exercise.' (38C; female; 75yrs)

A hierarchy of illnesses

None of the participants described their heart problem in terms of a chronic condition, or indicated that their MI was symptomatic of underlying heart disease.

'I never thought of the heart at all...it didn't seem to bother me...I felt good, you know. I didn't have any irregular beats, anything like that, so I didn't have a problem, so I didn't think about it. I still don't have a problem... The heart has 
cleared up and I've had no trouble since.' (7A; male 71yrs)

Participants' perceptions of other existing co-morbid illnesses as more symptomatic and functionally debilitating appeared to support the demotion of their heart problems within this 'hierarchy of illnesses'. Unlike pre-existing conditions which have been incorporated as part of the individual's identity, the heart condition does not readily fit within these personal schemas, and hence, patients may show more tendency to attribute health-related symptoms to these other conditions.

'I still put everything down to asthma...because I've always had asthma. I'm used to dealing with it. I suppose the simple fact is that if I ignore my heart that it might go away. Can you understand that?' (1C; female, 83 yrs)

For some participants, a long interval between a first and subsequent MI, or the achievement of reaching a particular age indicated to them that their existing methods of management must be effective.

'You see I survived for 12 years... what you done so well for them 12 years...I didn't think it was worth my while going in [to CR].' (7A; male 71yrs)

Participants' beliefs about their heart problems may also have been compounded by their recall of health professionals having described their heart-attack as 'mild'.

'Well, the thing is, it [the heart attack] they said it was a very very mild one, about a year and a half, a year last March... and I had this very, sort of... palpitations, you know, rapid pulse, very uncomfortable... So I went into the Lagan Valley, and I was there for about 5 days, and then everything seemed to get back to normal.' (5B; male, 65 yrs)

\section{Discussion}

Our analysis shows how patients who had not attended CR following a myocardial 
infarction had misperceptions about the nature and level of exercise required for cardiovascular benefit: they did not believe that CR attendance would confer additional benefit beyond that derived from engaging in activities of daily living.

Participants were not well informed about CR and perceived it to be primarily focused on exercise, rather than an integrated programme of various components - findings which are congruent with the results of previous research (Cooper et al., 2005; Cooper et al., 2007; Wingham, Dalal, Sweeney, \& Evans, 2006). It appeared that the perceived effectiveness and necessity of CR and exercise for physical health outcomes was fairly minimal. Cooper et al. (2005) have also reported misconceptions about the role of exercise in recovery from MI, and argue that these treatment related beliefs are closely connected with illness beliefs, especially cardiac misconceptions of an MI as a discrete event unconnected with underlying chronic disease processes (Cooper et al., 2005). Other research evidence (French, Maissi, \& Marteau, 2005) reveals the complexity of cardiac patients' causal attributions, where patients may acknowledge a range of contributory factors (including behavioural variables) - but as a trigger of the acute event, rather than part of the underlying chronic process that eventually yielded that event. Our participants (particularly those who were older) emphasised their perceptions of the influence of external factors, such as fate, familial disposition and medication on health outcomes and longevity. This is also in keeping with previous findings (French et al., 2006; Petrie et al., 1996) that those who did not believe that CR was necessary to improve their health or reduce the chances of recurrence of MI were less likely to attend. It appeared that CR may be perceived (by non-attenders) as a 'course', aimed at helping them return to a level of functioning within their social setting, rather than a mechanism for long term sustained behaviour change or improved health status. 
Many participants believed that they engaged in sufficient activity by doing housework or shopping, that social and psychological benefits were derived from these activities, and that such activities were sufficient for health. Current health advice recommends that moderate intensity exercise, for cardiovascular benefit, should result in the individual 'breathing more heavily than normal and feeling slightly warmer' (British Heart Foundation, 2007) but many participants reported that they would purposefully avoid this. Their apprehension about becoming breathless may be associated with their MI experience (Cooper et al., 2007). Indeed, many (but not all) participants expressed concern about the risk of MI recurrence or damage to their health through exertion. Hence, MI sufferers may focus on remaining active, engaging in activity which can be incorporated into daily tasks but not in exercise which may be of benefit to their cardiovascular health. The Birmingham Rehabilitation Uptake Maximisation Study (BRUM) (Jolly, Taylor, Lip, Greenfield, Raftery et al., 2007) also described these important differences between lay understandings of exercise, and the medical model. Home-based programmes have been suggested as an alternative for those for whom formal programmes are not acceptable (Dahal, Evans, Campbell, Taylor, Watt et al., 2007; Wingham, Dahal, Sweeney, \& Evans, 2006), as they may overcome some of the practical barriers associated with traditional cardiac rehabilitation programmes. However, they also involve a substantial exercise component, and while such programmes may be able to exploit the 'functional' model of exercise described by our participants, they will also need to take cognizance of the complex personal beliefs about exercise held by post-MI patients.

Data from the present study suggest that implicit and explicit cues are picked up from health professionals regarding the value which they attribute to CR and exercise, and that these may influence beliefs of the patient and their family about illnesses and 
treatments. The importance of health workers' communication in influencing CR attendance has been highlighted previously (Thornhill \& Stevens, 1998). While it is not possible to determine (given the retrospective recall by participants) the accuracy or specific content of health professionals' communication, it is the patient's interpretation of this information, and its integration into their individual illness schemas that is interesting. CR guidelines recommend that health professionals address illness-related concerns and correct misperceptions (Thompson, Bowman, Kitson, deBono, \& Hopkins, 1997). Previous research has also highlighted the value that patients attribute to the provision of specific tailored advice, monitoring and support (Wingham et al., 2006). It is therefore necessary to solicit patients' own illness and treatment representations (the perception of an MI as an isolated discrete event, failure to recognize the underlying chronic nature of CHD, perceived characteristics and efficacy of $\mathrm{CR}$ and recommended exercise), and their specific concerns about other medical conditions, so that advice can be delivered effectively within the context of the patients existing beliefs, and the opportunities for behaviour change maximized. More general advice, such as 'try to stay active' may not be interpreted (by the patient or their family) in the manner intended, and may lead to misunderstandings regarding the importance of moderate intensity aerobic exercise in the recovery process. Most existing interventions aimed at improving uptake of CR use motivational pamphlets and conversations with health professionals (Wyer, Earll, Joseph, Giles \& Johnston, 2001; Jolly, Bradley, Sharp, Smith, Thompson et al., 1999). Several authors have recommended efforts to modify illness beliefs among post-MI patients (Cooper et al., 1999; Wyer et al., 2001). Our data suggest that it would also be appropriate to address beliefs about treatment (CR and exercise) efficacy in addition to illness perceptions when $\mathrm{CR}$ is presented to potential users, an approach also advocated by Cooper et al. (2007) and French 
et al. (2005). An understanding of how CR programmes (and exercise) can help is necessary, as patients who are unsure of these mechanisms are more likely to cite possible barriers to attendance (Cooper et al., 2007). Patients should be helped to understand the multi-dimensional nature of $\mathrm{CR}$, and its effects on both physical and psychological outcomes, risk of recurrence and longevity. Psychological interventions to elicit and modify beliefs, and to promote CR attendance should ideally occur at the time of invitation or during the patient's stay in hospital post-MI. Such interventions could be based upon an extension of Leventhal's self-regulatory model - the 'necessity-concerns framework' (Horne, 1997), which describes the role of patients' beliefs about the necessity and possible costs associated with their treatment. Social cognition models such as the Theory of Planned Behaviour (TPB) (Ajzen \& Madden, 1986) or the Health Belief Model (HBM) (Rosenstock, 1974) which incorporate important illness beliefs (perceived severity and perceived susceptibility in the HBM) while also representing beliefs about treatment (perceived costs and benefits in the HBM) may also provide useful frameworks. The TPB also recognises the influence of important others (subjective norms) in influencing the intention to engage in a specific health behaviour: its use in an invitation to CR for post-MI patients has been associated with increased CR uptake (Wyer et al., 2001).

The present study's design limits the ability to generalise beyond the study sample, particularly to societies which are more culturally diverse than Northern Ireland. It is also not possible to determine the relative importance of specific illness or treatment beliefs, nor is it possible to draw a direct relationship between beliefs about exercise and the decision not to attend CR, as the interviews were conducted after this decision was made and the beliefs reported at interview may have been modified by various sources in the interim. It is possible that interviews at the time of decision would produce different data, as illness 
cognitions evolve over time (Leventhal, Nerenz \& Steele, 1984; Gudmundsdóttir, Johnston, Johnston, \& Foulkes, 2001). However, interviews prior to decisions about attendance may not accurately reflect relationships between attendance and beliefs: the interview process itself may act as a cue for attendance. Similarly, studies seeking to compare beliefs of people who attend CR with those of non-attenders are problematic as attenders' beliefs may reflect knowledge gained from attendance.

\section{Conclusion}

The efficacy of CR and exercise for improving physical health outcomes and for secondary prevention are not well understood by non-attenders of CR. We suggest that uptake of CR could be promoted by better communication and explanation of these relationships, especially the health benefits of exercise. This communication should demonstrate to potential participants that significant others, especially health professionals, consider exercise important and valuable. These findings can inform future research on the effectiveness of different theoretical approaches in the design of simple interventions aimed at increasing CR uptake. 


\section{References}

Ades, P.A., Waldman, M.L., McCann, W.J., \& Weaver, S.O. (1996). Predictors of cardiac rehabilitation participation in older coronary patients. Archives of Internal Medicine, 152, 1033-1035.

Ajzen, I., \& Madden, T.J. (1986). Prediction of goal-directed behaviour: attitudes, intentions, and perceived behavioural control. Journal of Experimental Social Psychology, 22, 453-474.

Blanchard, C.M., Reid, R.D., Morrin, L.I., Beaton, L.J., Pipe, A., et al. (2006). Correlates of physical activity change in patients not attending cardiac rehabilitation. Journal of Cardiopulmonary Rehabilitation, 26, 377-83.

British Heart Foundation. (2007). Get active for your heart. Retrieved 20 June 2007, from http://www.bhf.org.uk/keeping_your_heart_healthy/staying_active/get_active for your heart.aspx

Clark, A.M., Whelan, H.K., Barbour, R., MacIntyre, P.D. (2005). A realist study of the mechanisms of cardiac rehabilitation. Journal of Advanced Nursing, 52, 362-371.

Cooper, A.F., Jackson, G., Weinman, J., \& Horne, R. (2005). A qualitative study investigating patients' beliefs about cardiac rehabilitation. $\underline{\text { Clinical Rehabilitation, }}$ $\underline{19}, 87-96$.

Cooper, A., Lloyd, G., Weinman, J., \& Jackson, G. (1999). Why patients do not attend cardiac rehabilitation: role of intentions and illness beliefs. Heart, 82, 234-236.

Cooper, A.F., Weinman, J., Hankins, M., Jackson, G., \& Horne, R. (2007). Assessing patients' beliefs about cardiac rehabilitation as a basis for predicting attendance after acute myocardial infarction. Heart, 93, 53-58. 
Creswell, J.W. (2003). Research design: qualitative, quantitative and mixed methods approaches, 2nd ed. London: Sage Publications.

Dahal, H.M., Evans, P.H., Campbell, J.L., Taylor, R.S., Watt, A., Read, K.L.Q., et al. (2007). Home-based versus hospital-based rehabilitation after myocardial infarction: A randomized trial with preference arms - Cornwall Heart Attack Rehabilitation Management Study (CHARMS). International Journal of Cardiology, $\underline{119}, 202-211$.

French, D.P., Cooper, A., \& Weinman, J. (2006). Illness perceptions predict attendance at cardiac rehabilitation following acute myocardial infarction: A systematic review with meta-analysis. Journal of Psychosomatic Research, 61, 757-767.

French, D.P., Lewin, R.J.P., Watson, N., \& Thompson, D.R. (2005). Do illness perceptions predict attendance at cardiac rehabilitation and quality of life following myocardial infarction? Journal of Psychosomatic Research, 59, 315-322.

French, D.P., Maissi, E., \& Marteau, T.M. (2005). The purpose of attributing cause: beliefs about the causes of myocardial infarction. Social Science and Medicine, 60, 14111421.

Greenhalgh, T., \& Taylor, R. (1997). How to read a paper: papers that go beyond numbers (qualitative research). British Medical Journal, 315, 740-43.

Gudmundsdóttir, H., Johnston, M., Johnston, D., \& Foulkes, J. (2001). Spontaneous, elicited and cued causal attributions in the year following a first myocardial infarction. British Journal of Health Psychology, 6, 81-96.

Horne, R. (1999). Patients' beliefs about treatment: the hidden determinant of treatment outcome? Journal of Psychosomatic Research, 47, 491-95. 
Jolly, K., Bradley, F., Sharp, S., Smith, H., Thompson, S., Kinmonth, A.L., \& Mant, D. (1999). Randomised controlled trial of follow up care in general practice of patients with myocardial infarction and angina: final results of the Southampton heart integrated care project (SHIP). British Medical Journal, 318, 706-711.

Jolly, K., Taylor, R., Lip, G.Y.H., Greenfield, S., Raftery, J., Mant, J., et al. (2007). The Birmingham Rehabilitation Uptake Maximisation Study (BRUM). Home-based compared with hospital-based cardiac rehabilitation in a multi-ethnic population: cost-effectiveness and patient adherence. Health Technology Assessments, 11, No 35.

Leventhal, H., Meyer, D., \& Nerenz, D. (1980). The common sense representation of illness danger. In S Rachman (Ed.), Contributions to medical psychology (pp. 1730). New York: Pergamon Press.

Leventhal, H., Nerenz, D.R., \& Steele, D.J. (1984). Illness representations and coping with health threats. In E. Baum, S.E. Taylor, \& J.E. Singer (Eds.), Handbook of psychology and health, vol 4. (pp. 219-251). Hillsdale, NJ: Erlbaum.

MacInnes, JD. (2005). The illness perceptions of women following acute myocardial infarction: Implications for behaviour change and attendance at cardiac rehabilitation. Women and Health, 42, 105-121.

Melville, M.R., Packham, C., Brown, N., Weston, C., \& Gray, D. (1999). Cardiac rehabilitation: socially deprived patients are less likely to attend but patients ineligible for thrombolysis are less likely to be invited. Heart, 15, 288-96.

Pell, J., Pell, A.C., Blatchford, O., \& Dargie, H. (1996). Retrospective study of influence of deprivation on uptake of cardiac rehabilitation. British Medical Journal, 313, 267- 
68.

Petrie, K.J., Weinman, J., Sharpe, N., \& Buckley, J. (1996). Role of patients' view of their illness in predicting return to work and functioning after myocardial infarction: longitudinal study. British Medical Journal, 312, 1191-94.

Rosenstock, I.M. (1974). Historical origins of the health belief model. Health Education Monographs, 2, 354-86.

Taylor, R.S., Brown, A., Ebrahim, S., Jolliffe, J., Noorani, H., Rees, K., et al. (2004). Exercise-based rehabilitation for patients with coronary heart disease: Systematic review and meta-analysis of randomized controlled trials. American Journal of Medicine, 116, 682-692.

Thompson, D.R., Bowman, G., Kitson, A., de Bono, D., \& Hopkins, A. (1997). Guidelines and audit standards. In D.R. Thompson, G.S. Bowman, D.P. de Bono, \& A. Hopkins (Eds.), Cardiac rehabilitation: Guidelines and audit standards (pp. 119132). London: Royal College of Physicians.

Thornhill, M., \& Stevens, J.A. (1998). Client perceptions of a rural-based cardiac rehabilitation program: a grounded theory approach. Australian Journal of Rural Health, 6, 105-111.

Wingham, J., Dalal, H.M., Sweeney, K.G., \& Evans, P.H. (2006). Listening to patients: Choice in cardiac rehabilitation. European Journal of Cardiovascular Nursing, 5, 289-294.

Witt, B.J., Thomas, R.J., \& Roger, V.L. (2005). Cardiac Rehabilitation after myocardial infarction: a review to understand barriers to participation and potential solutions. Europa Medicophysica, 41, 27-34. 
Witt, B.J., Jacobsen, S.J., Weston, S.A., Killian, J.M., Meverden, R.A. et al. (2004).

Cardiac rehabilitation after myocardial infarction in the community. Journal of the American College of Cardiology, 44, 988-996.

Whitmarsh, A., Koutantji, M., \& Sidell, K. (2003). Illness perceptions, mood and coping in predicting attendance at cardiac rehabilitation. British Journal of Health Psychology, $\underline{8}, 209-221$.

Wyer, S., Earll, L., Joseph, S., Giles, M., \& Johnston M. (2001). Increasing attendance at a cardiac rehabilitation programme: an intervention using the Theory of Planned Behaviour. Coronary Health Care, 5, 1-6.

Wyer, S.J., Earll, L., Joseph, S., \& Harrison, J. (2001). Deciding whether to attend a cardiac rehabilitation programme: an interpretative phenomenological analysis. Coronary Health Care, 5, 178-188.

Wyer, S.J., Joseph, S., \& Earll, L. (2001). Predicting attendance at cardiac rehabilitation: a review and recommendations. Coronary Health Care, 5, 171-177. 